\title{
Acceptance of the Abolition of New Year's Eve Fireworks: A Theoretical and Empirical Analysis under the Aspect of Sustainability
}

\author{
By Wanja Wellbrock ${ }^{1}$, Daniela Ludin ${ }^{1}$, Erika Müller ${ }^{1}$, Maximilian Weiß ${ }^{1}$, \\ Matthias Zeh ${ }^{1}$, Wolfgang Gerstlberger ${ }^{2}$
}

\begin{abstract}
Actually, discussions about a prohibition of fireworks are becoming more and more fluent. This topic is discussed in this paper in an empirically comprehensible manner, including sustainability aspects. The aim of the paper is to determine to what extent fireworks are harmful to people and the environment and under what circumstances citizens are prepared to dispense New Year's Eve fireworks. At the same time, it is unclear who is responsible for these issues. Politics are often blamed for solving problems like this, especially when there is no clear opinion in society. On the other hand, political intervention is in clear conflict with the free market economy and the independent economic actions of individuals. The study is based on a survey carried out in the city of Schwäbisch Hall. A valid database was created to achieve trustful data. The definition of concrete recommendations for action that can be applied in Schwäbisch Hall is another result of this paper.
\end{abstract}

Keywords: Fireworks, sustainability, theoretical analysis, empirical analysis

\section{Introduction}

„Why should I be studying for a future that soon may be no more, when no one is doing anything to save the future?"(Greta Thunberg, n.d.)

The well-known and much-discussed climate activist Greta Thunberg has initiated discussions on climate protection on many levels, not only on the global political level, but also on the local level. Many young people have followed Greta's example and participated or even organized protests for climate protection and a securement of their future living conditions. In 2019, following an initiative of the local Friday's for Future movement, the city of Constance was the first German municipality that announced the state of "climate emergency" (Röhlig, 2020). By declaring the climate emergency, Constance has committed itself to become carbon-free by 2030 and to evaluate all decisions made by the city council according to their climate impact (Alianza del Clima e.V., n.d.). Despite the climate emergency and the increasing awareness about the necessity of climate protection measures on local level, the citizens of Constance are hesitant to give up the annual fireworks of the "Seenachtfest". This firework shoots many thousands of euros and vast quantities of fine dust particles into the air (Südwestrundfunk, 2019).

A ban on firework shoots is not only debated in Constance, but hits on points 
corresponding with discussions taking place in other German cities as well. Last year, the city of Schwäbisch Hall has tested an alternative to classical fireworks as part of one of its annual city festivals. One of the main reasons for that choice was not connected to fine dust particles, rather than to issues of fire prevention in the historical city center (Acker, 2019, para. 4). However, the interest of this study is to receive a realistic and valid overview how citizens of Schwäbisch Hall would perceive a general ban of fireworks by developing an empirical study. An additional aim is to determine to what extent fireworks are harmful to people and the environment and under what circumstances citizens are prepared to forgo New Year's Eve fireworks. Besides that, responsibilities linked to fireworks shall be discussed. Politics are often blamed for solving problems like this, especially when there is no clear opinion in society. On the other hand, political intervention is in clear conflict with the free market economy and independent economic actions of individuals. The individual aspects of this conflict should be separated and considered from different perspectives. A conducted survey shall help to create a valid database, regardless of emotionally charged debates and to define concrete recommendations for Schwäbisch Hall.

\section{Methodology}

In the procedure of writing the scientific paper, research leading questions were created to identify the most important fields of research (Table 1). By separating the scientific fields of materials science (no. 1 to 4), sustainability sciences (no. 5 to 10), climate policy (no. 11 and 12), and behavioural economics (no. 13 to 18), the thematic context was integrated into existing science. By assigning the research leading questions to the individual scientific fields, the object of investigation was thus linked to scientific foundations. Different methodological approaches to research were used, such as surveys or literature searches. In addition to observation and experiment, the following methods were used to systematically analyse social reality (Atteslander, 2010, p. 54):

\section{Table 1: Research leading questions. Source: Own Representation}

\begin{tabular}{|c|c|c|c|}
\hline Nr. & Research leading questions & Chapter & Methodology \\
\hline 1 & How much fine dust is emitted by fireworks? & 3 & Literature research \\
\hline 2 & What alternatives are possible? & 3 & Literature research \\
\hline 3 & What's fireworks? & 3 & Literature research \\
\hline 4 & Does the population know about the harmfulness of fireworks? & 4 & Survey \\
\hline 5 & What are the consequences of igniting fireworks? & 3 & Literature research \\
\hline 6 & Which of these alternatives are sustainable? & 3 & Literature research \\
\hline 7 & Is there a concrete need for action in this topic? & 4 & Survey \\
\hline 8 & Would the global abandonment of fireworks lead to a verifiable improvement of the climate? & 3 & Literature research \\
\hline 9 & What local improvements would a abandonment bring about? & 4 & Literature research \\
\hline 10 & What is sustainability? & 3 & Literature research \\
\hline 11 & Is political action necessary or social change? & 4 & Survey \\
\hline 12 & What are the political options? & 4 & Literature research \\
\hline 13 & How many fireworks are ignited on average in Schwäbisch Hall? & 3 & Census \\
\hline 14 & To what degree are the citizens of Schwäbisch Hall willing to forego individual fireworks? & 4 & Survey \\
\hline 15 & Which incentives are crucial for the abandonment? & 4 & Survey \\
\hline 16 & What alternatives are attractive for the citizens of Schwäbisch Hall? & 4 & Survey \\
\hline 17 & How much money do the citizens of Schwäbisch Hall spend on fireworks every year? & 4 & Survey \\
\hline 18 & What percentage of citizens in Schwäbisch Hall ignite fireworks every year? & 4 & Census \\
\hline
\end{tabular}




\subsection{Literature analysis}

In literature analysis, all forms of literature such as texts, pictures, films, and other contents are used as a basis for knowledge (Atteslander, 2010, p. 195). In this study, the focus was on text analysis, a form of literature analysis, including empirical and hermeneutical content analysis. This form of analysis is characterized by the thematic sequence of the following described steps: After the definition of the problem, several central questions arise that define the focus of this study (Balzert et al., 2011, p. 283). In our case, we examined aspects related to "particulate matter pollution from fireworks in Schwäbisch Hall" and the resulting research questions (Table 1). Problem areas correlating with the area of investigation were defined and have been outlined with a selection of suitable materials. Materials used included specialist literature, specialist journals of the last 5 years and online websites, like the official website of the city of Schwäbisch Hall. Using the online database "BOSS", suitable articles from relevant journals were screened. First, individual articles found were assigned to the scientific fields, followed by a detailed analysis of the content, which builds an important basis for obtaining, recording and consequently interpreting results (Balzert et al., 2011, p. 283).

\subsection{Document analysis}

The goal-oriented and systematic collection and archiving of already existing documents is called document analysis in science. The evaluation of the collected documents includes qualitative and quantitative processing of the information obtained (Balzert et al., 2011, p. 537). Especially for newspaper articles, radio and television broadcasts, online documents or documents from official organizations, scientific document analysis is used as a form of literature research (Balzert et al., 2011, p. 539). This analysis has been used for this study.

\subsection{Survey}

Atteslander defines a survey as communication between two or more people. A survey does not capture social behaviour as a whole, but only verbal behaviour as a partial aspect (Atteslander, 2010, p. 109). Censuses are also carried out to obtain a quantitative component of (consumer) behaviour as partial aspect of social behaviour. In quantitative research, fully structured written surveys often replace qualitative verbal interviews (Döring \& Bortz, 2016, pp. 398-400).

The development of an appropriate questionnaire took place in two steps. First, a rough concept was drafted in which the basic structure was set out. Based on this rough concept, relevant questions were pre-formulated. In relation to content, all scientific fields had to be covered by at least one question. The questions should be as simple as possible so that the respondents, who might not be familiar with the topic, were able to provide answers. In a second step, questions were arranged in a logical order following the central theme in the detailed concept. Finally, the layout of the questionnaire was structured and designed in a modern way (Döring \& Bortz, 2016, pp. 405-407).

The "Umfrageonline.de" platform was chosen as survey medium. Additionally to a simple application for the participants, this platform also offers a variety of evaluation methods and is free of advertising, spam, and viruses. After creating the questionnaire, a qualitative and quantitative pre-test was conducted (Döring \& Bortz, 2016, p. 411). In 
this test, the questionnaire was pre-checked by 10 testers for comprehensibility, type of items, answer formats and relevant errors. In addition, suggestions for improvement were obtained and implemented (Döring \& Bortz, 2016, p. 411). The survey was made accessible to the public via a survey link. The Facebook group "Schwäbisch Hall" was used as a multiplier, which has more than 13,000 members.

\section{Theory}

\subsection{Fields of Sciences}

The present study focuses on the scientific fields of materials science, sustainability science, climate policy, and behavioural economics and their interdependences (Figure 1). It examines the individual behaviour of citizens in Schwäbisch Hall and the surrounding area as well as the political scope for action.

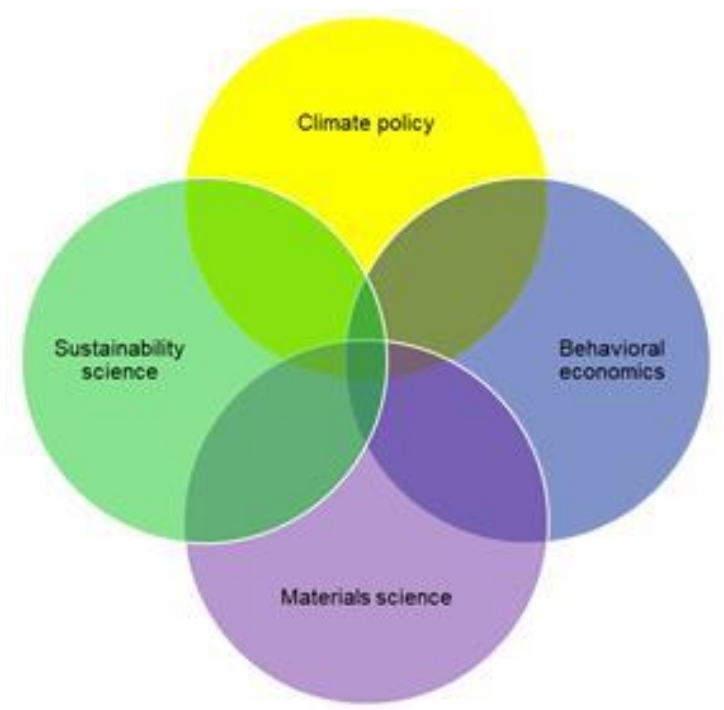

Figure 1: Interdependence of fields of sciences, used in this study

Source: Own representation

\subsection{Materials science}

The use of fireworks is a worldwide tradition to celebrate religious festivals, political and sporting events. Probably the most famous events to ignite fireworks are the Lantern Festivals in China and Taiwan, Independence Day in the USA and New Year's celebrations around the world. Besides cheerfulness and joy at the festivities, fireworks cause one thing in particular: air pollutants (Tanda et al., 2019, p. 371). An analysis of single-particle mass spectrometry revealed five different types of single particles, which signify as "fine dust": organic carbon sulphate, ash, dust, metal, and biomasses in different size distributions. In addition, chemical reactions in the air, generated during the burning of fireworks lead to secondary particles like sulphate and nitrate. In 2016, the Research Centre for Ecological and Environmental Sciences of the Chinese Academy of Science was able to prove that these chemical reactions, leading to a release of aerosols, 
also contribute to the generation of fine dust during fireworks (Li et al., 2016, p. 184).

Researchers from the University of Groningen, in cooperation with other universities and institutes in the Netherlands, have analysed the fine dust pollution during New Year's Eve celebrations from 1995-2012. The average concentration of fine dust particles in the Netherlands from 27-30 December is about $29 \mu / \mathrm{m}^{3}$, which is significantly below the already mentioned EU limit of $40 \mu / \mathrm{m}^{3}$. In the first few hours of the New Year, particulate matter pollution in the highly populated areas increased to up to $598 \mu / \mathrm{m}^{3}$. This is 15 times higher than the specified EU limit for respirable particulate matter (Greven et al., 2019, p. 1).

In addition to health risks caused by particulate matter and injuries and accidents caused by the explosive power of fireworks, there are also serious ecological consequences due to the pollution ( $\mathrm{Li}$ et al., 2016, p. 185). These mainly affect local fine dust problems, which have already been discussed in major German cities, such as Constance. Maike Sippel, the climate protector of Constance, concludes that greenhouse gases caused by fireworks are relatively low and therefore do not affect the climate balance of Constance at all (Südwestrundfunk, 2019). Nevertheless, a large number of people are affected by health risks every year. The majority of injuries affect the hands and face. It is particularly remarkable that between 1999 and 2014 injuries did not decrease, which shows the apparently weak learning effect of the population (Sandvall et al., 2017, p. 1469). European studies showed that $45 \%$ of fireworks injuries affect the eyes, causing serious long-term damage. A large percentage of the injured persons (about 56\%) are not responsible for firing the fireworks (so-called "bystander"); the thesis leaves open to what extent regulation of fireworks activities is a political issue in order to protect the uninvolved total population (Huth et al., 2019, p. 1171).

No studies have been carried out until today dealing with the risk of injuries caused by public fireworks.

\subsection{Sustainability sciences}

The term "sustainability" in its original sense was first used in 1713 in the "sylviculture economic" by Hans Carl v. Carlowitz. He recognized that more wood was needed for the construction and operation of his silver mines than could grow back in the same period. Consequently, his goal was to use only as much wood as could grow back (Edeltraud et al., 2015, p. 269f.; comp. Morscher, 2015, p. 661). His theory was taken up again because of a debate on sustainability in 1972. In this debate, population growth combined with the increasing demand for non-regenerative resources came into conflict (Edeltraud et al., 2015, p. 269f; comp. Morscher, 2015, p. 661). It was supplemented by social aspects 15 years later in the "Brundtland Report". Thus, not only problems with the ecologically sustainable resource use were addressed, but also economic development associated with social problems. The central hypothesis of the "Brundtland Report" is that "sustainable development seeks to meet the needs and aspirations of the present without compromising the ability to meet those of the future" (Morscher, 2015, p. 661). Thus, each generation should be enabled to have the same basic conditions. The concept of sustainability is considered so essential that it was declared as a guiding policy principle in the 1992 UN Conference on Environment and Development. The aspects of sustainability gathered in a historical context are today 
graphically represented in a well-known and scientifically proven three-pillar model. As this model is the basis for many definitions of sustainability, it is taken up from many different viewpoints (Edeltraud et al., 2015, p. 269f; comp. Morscher, 2015, p. 661).

\subsection{Climate policy}

Protecting the climate has been a major political issue for many years. From a political point of view, climate protection signifies to reduce environmentally harmful emissions. The measurement of harmful fine dust particles in the air is an important prerequisite for monitoring the achievement of targets. The Particulate Matter Index (PM), which defines the size of fine dust particles, is a crucial indicator (Bischoff, 2014, p. 156). The main parameters defined here are PM10 and PM2.5, describing "inhalable fine dust where the aerodynamic diameter of the particles is less than $10 \mu \mathrm{m}$ " (Bischoff, 2014, p. 156). PM2.5, in turn, is recorded as the "respirable fine dust" with a particle diameter of $2.5 \mu \mathrm{m}$ (Bischoff, 2014, p. 156).

These measurement parameters are used to define both global and country-specific limits. In international comparison, the European Union sets the highest limits, with an annual average of 40 PM10 and 25 PM2.5 per cubic meter of air. The USA, Singapore, and Japan have limit values that are only about half as high. The significantly stricter PM2.5 limit value of 10 and PM10 limit value of 20 set by the World Health Organization (WHO) is not complied by any of the nations listed (Spannowsky, 2019, p. 435).

Besides these reference values, additive targets are set in Germany in a "Climate Protection Plan 2050" that aims to reduce emissions of greenhouse gases by $80-95 \%$ in 2050 compared to 1990. An interim goal is to reduce greenhouse gas emissions by $40 \%$ in 2020. Germany has major problems in achieving its particulate matter targets, especially in urban areas. In Stuttgart, e.g., a daily average value of over $50 \mu \mathrm{g} / \mathrm{m}^{3}$ was measured in 2013. The daily average limit was exceeded 82 times. In Gelsenkirchen and Leipzig, these values exceeded 57 and 42 times the average daily limit. Looking at all 386 fine dust measuring stations in Germany, it can be noted that the daily average limit was exceeded at 98 stations. This illustrates how far Germany is from the proposed WHO standards despite the measures already taken.

\subsection{Behavioural economics}

Behavioural economics is based on the concept of the "Homo oeconomicus" that describes humans as self-serving and egotistical consuming creatures. Within the framework of behavioural economics, humans do not only act as radical benefit maximizers, but a variety of factors such as "environmental interests" or social issues influence economic behaviour. Consumption forms one essential component (A. u., 2017, p. 1200). In this context, consumer behaviour refers to the decision of an end consumer to purchase goods or services. A multitude of individual criteria such as the inner mindset influences both the choice of brand and shopping location. The time of purchase and quantity consumed is also influenced, as well as the specific supplier, product and purchasing process (Dechêne, 2016, p. 905).

The boom in behavioural economics began after the worldwide financial and economic crisis in 2008 when it became clear that economics cannot be defined by scientific laws 
alone, but are also influenced by moods and expectations. Maximizing benefits is not the only focus of human behaviour. Other driving forces and explanation models must also be considered, which are now reflected in behavioural economics through psychological and socio-psychological discoveries (A. u., 2017, p. 1200). Richard H. Thaler used these discoveries in his "Nudging" theory, published in 2008. "Nudging" through incentive systems aims to influence behavioural economic decisions in both private and public contexts (A. u., 2017, p. 1201). By critically analysing the original concept of Homo oeconomicus, which was highly appreciated by many economists and popular due to its simplicity but not close to reality, the gentle paternalism was born (Badenberg, 2016, p. 283). The basic idea here was to manipulate people for their own benefit (A. U., 2017, p. 1201) in order to make a positive impact on the lives of citizens (Badenberg, 2016, p. 283). In contrast, however, it is important not to fall into a dictatorial paternalism in which intervention in the economy is linked to a loss of individual freedom (A. u., 2015, p. 54). Basically, state intervention is intended to make it easier and simpler for people to use freedom without materially restricting their freedom (A. u., 2015, p. 54). In summary, modern behavioural economics is characterized by both "nudging" and paternalism. For this purpose, consumer behaviour of individuals is observed in order to positively influence it from a state perspective. At the same time, the freedom of consumers should not be restricted (A. u., 2015, p. 54).

\section{Empiricism}

\subsection{Data basis}

All adult citizens of the Schwäbisch Hall district were considered to be subject of this study. In order to be able to classify the results of the survey, personal data such as place of residence, gender and age were requested. Since the purchase of fireworks is only legal from the age of 18, the survey was designed directly for this target group. The survey was published online in the early evening of 22 nd November 2019. Due to a large number of participants, the survey was closed already about 48 hours after publication on Sunday evening, November 24 ${ }^{\text {th }}, 2019$. This was necessary in order to be able to carry out a valid evaluation of the individual data, as the evaluation of the many empty fields, in particular, involves a great deal of effort. In total, 187 participants attended; $62 \%$ were female, 37\% male and 1\% diverse. The age ranged from 18 to 70 years, with an average age of 31 years. $66 \%$ of the participants were direct residents of the city of Schwäbisch Hall, the remaining $34 \%$ came from the surrounding villages of the district of Schwäbisch Hall. The high number of participants in a very short time shows the extremely high interest of the population in this current topic.

\subsection{Results from a sustainability perspective}

As Maike Sippel has already pointed out, the consumption of fireworks does not have a significant influence on the climate goals of Constance. However, since the total amount of particulate matter emitted by fireworks in Germany is roughly equivalent to the emissions of 18 full days from all German motor vehicles, they should not be neglected. In order to reduce emissions, information on the environmental impact of fireworks is particularly needed. Survey respondents were asked to assess the particulate 
emissions of fireworks ignited in Germany based on the above-mentioned example of the automotive industry. The actual amount of particulate matter emitted by fireworks in Germany is 1,400 tons per year. Only about $5 \%$ of the respondents gave an estimate within a realistic target corridor of 400 to 2,400 tons. This implies the lack of understanding of the actual environmental impact of fireworks among the population. Chapter 4.4 Behavioural economics discusses possible alternatives to fireworks, which are harmless from a sustainability point of view. Only community fireworks, frequently mentioned in the survey, violate the defined sustainability concept. Sustainability of a joint firework display is strongly dependent on type and size; therefore, no generally valid statement can be made. A community firework display is more sustainable, however, because fine dust and carbon dioxide emissions can exactly be measured, controlled and regulated. Fine dust represents a considerable health hazard; particulate matter is one of the most important causes of early death. The effects on health can be manifold, e.g., loss of lung function, heart attack, cardiac arrhythmia, allergies, and asthma. This possibly affects fireworks igniters, but also bystanders and is a sustainability issue from a health point of view. Banning local fireworks could help to improve the air quality, especially in large cities.

\subsection{Results from a climate policy perspective}

Implementing effective climate protection measures is of great importance. In this context, climate targets for carbon dioxide emissions and limit values for fine dust pollution of PM2.5 and PM10 are already part of the climate protection plan 2050. Exactly these fine dust particles are released during fireworks. In consumer policy, the principle of paternalism applies. Here, the conflict between government's regulations and incentives and the resulting loss of individual freedom has already been addressed. Citizens of Schwäbisch Hall and the surrounding area were asked whether they see a concrete need for action to combat New Year's Eve fireworks induced fine dust pollution. The clear majority (61\%) saw a concrete need for action. The core question, however, is who is responsible for necessary action. $65 \%$ of the participants saw society and politics as equally responsible, $28 \%$ mentioned only society as responsible and $6 \%$ only politics. Therefore, $93 \%$ of participants were of the opinion that society needs to reconsider its point of view and $71 \%$ favoured politicians to do so. Interestingly participants saw themselves primarily as responsible, which might imply rethinking personal consumer behaviour. Consequently, there is a need for action, especially at the municipal level. The majority of those surveyed were in favour of this rethinking being supported by local politics.

Figure 2, which was prepared according to the "Net Promotor Score", shows that the respondents are largely satisfied with the current fireworks ban in the city centre of Schwäbisch Hall (average satisfaction of 6.99 points). The local ban in the city centre leads to a clear enthusiasm of more than $50 \%$ of the population. This benefit, in the sense of paternalism, clearly exceeds the loss of freedom associated with the ban. However, if this local ban were extended to the entire district, the associated satisfaction score would drop by almost $20 \%$. 


\begin{tabular}{|c|c|c|c|c|c|c|c|c|c|c|c|}
\hline Evaluation & 0 & 1 & 2 & 3 & 4 & 5 & 6 & 7 & 8 & 9 & 10 \\
\hline Quantity & 24 & 4 & 3 & 10 & 2 & 22 & 3 & 5 & 18 & 8 & 88 \\
\hline
\end{tabular}

Satisfaction with the extension of the ban to the entire district

\begin{tabular}{rl|c|c|c|c|c|c|c|c|c|c|c|} 
Evaluation & 0 & 1 & 2 & 3 & 4 & 5 & 6 & 7 & 8 & 9 & 10 \\
\cline { 2 - 13 } Quantity & 53 & 5 & 1 & 6 & 6 & 22 & 1 & 6 & 11 & 5 & 71 \\
& $\rightarrow$ Average satisfaction: 5,61
\end{tabular}

Figure 2: Citizen's satisfaction with inner city firework ban

Source: Own representation.

This decline in satisfaction suggests that holistic prohibitions and the resulting loss of freedom lead to greater dissatisfaction. This underlines the fact that local bans in endangered areas are tolerated and desired by the population, but comprehensive bans are undesirable. This insight can be transferred to a national perspective, so that bans in endangered areas, as in the example of Stuttgart, which has already been taken up, certainly lead to greater satisfaction than nationwide bans. From a national perspective, therefore, other regulatory measures need to be considered, e.g., introducing emission limits for fine dust particles caused by fireworks. The results of the survey indicate that the fundamental problem of politics is to find a balance between benefits for the entire population and individual freedom.

\subsection{Results from a behavioural economics perspective}

"Behavioural economics" define consumer behaviour based on various concepts such as bomo oeconomicus, "nudging" and paternalism. However, the extent to which incentives and restrictions are necessary or permissible will be analysed in the following. Therefore, the survey also focused on consumer behaviour of the citizens of Schwäbisch Hall and the surrounding area by asking how many citizens consume fireworks in Schwäbisch Hall. 86 of 187 respondents stated that they buy New Year's Eve fireworks, representing a relative share of $46 \%$. An average purchase of fireworks costs about $35 €$, which can be compared to a per capita consumption of $16 €$ per citizen in Schwäbisch Hall. With 33,418 adult inhabitants in Schwäbisch Hall in 2018, this results in a fireworks consumption of almost 535,000€ per year (Stadt Schwäbisch Hall, 2019).

In all behavioural economic concepts, the benefit of an individual is central. In order to illustrate this benefit and to determine when the marginal utility is reached, citizens in Schwäbisch Hall were interviewed in our survey. Almost 25\% of fireworks buyers would stop buying fireworks if prices were to rise significantly. At this percentage of the population, the marginal benefit would already be reached. Another $30 \%$ of fireworks consumers would react to a price increase with lower demand. The marginal benefit has not yet been fully achieved, but the increase in benefit is nevertheless decreasing. For the remaining $45 \%$ of buyers, the increase in benefit is still so far removed from the marginal benefit that a significant price increase would have no effect on demand. From these 
results, it can be concluded that increasing prices might reduce the consumption of fireworks, but do not prevent it altogether. Therefore, the consumption of fireworks cannot be regulated by pricing policy alone, which is important for assessing regulatory options available to policymakers (see chapter 4.3).

In order to identify concrete benefits of lighting fireworks, participants were asked what kind of fireworks they consume. Participants obtained the greatest benefit from igniting rockets and fireworks batteries. Almost 55\% of fireworks buyers do consume these types of fireworks. $45 \%$ of fireworks fans use small fireworks like firecrackers, small volcanoes or fire spinning tops. Only 16\% prefer light firecrackers. Since multiple answers were permissible in the survey, it is also possible to be statistically recorded in all three categories. Consequently, it can be assumed that the benefit of igniting New Year's Eve fireworks is not the banging explosions, but rather the light effects are decisive for the popularity of fireworks. This is a positive result in terms of risk assessment, as most injuries (37\%) are caused by the ignition of fireworks (Huth et al., 2019, p. 1173).

From a behavioural economics perspective, solutions need to satisfy above all psychological and socio-psychological aspects. Thus, the question was asked which conceivable alternatives are considered attractive by Schwäbisch Hall citizens. In a supported survey with additive-free answer possibilities, $50 \%$ of all respondents considered light and laser show an attractive substitution. However, if only fireworks consumers are considered, the popularity of light and laser shows shrinks to $35 \%$. In principle, lantern parades, New Year's Day fires, and fire shows were a conceivable alternative (Figure 3). For 36\% of fireworks consumers, fireworks would not be missed under any circumstances. Since multiple answers were allowed in this query, the following figures are shown with absolute numbers.
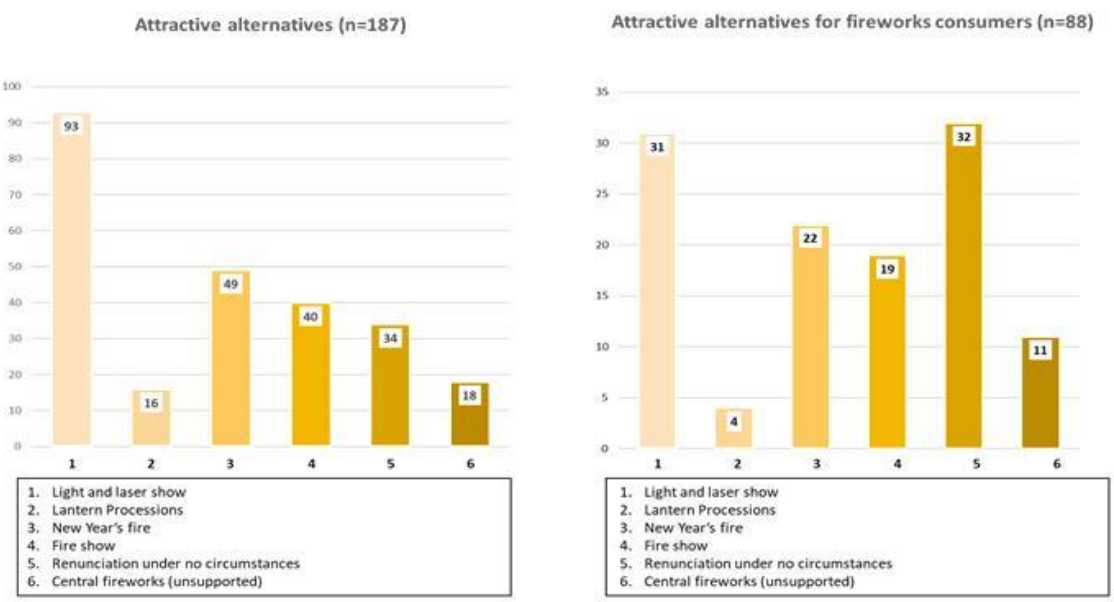

Figure 3: Attractive alternatives to fireworks

Source: Own representation.

About $10 \%$ of the participants additionally stated that a central firework display organized by the city would be a conceivable alternative to private fireworks. The fact that these answers were unsupported increases the weighting of this alternative 
considerably. However, this represents only one possibility to regulate and control the pollution caused by fireworks, but not to prevent it completely. The risk of injury from fireworks, which is dealt with in chapter 3.2 materials management, can be almost completely eliminated by this measure.

In summary, a variety of alternatives is attractive to the population of Schwäbisch Hall and the surrounding area. Due to the individuality of human consumer behaviour, however, no alternative could be found in this survey that is supported by the entire population.

\section{Limitations and Further Research}

\subsection{Limitations}

In conclusion, the chosen topic is absolutely at the heart of the matter and has aroused great interest among the population. This was particularly evident from the surprisingly high number of participants, so that the survey had to be closed after 48 hours. Many citizens became aware of the survey by the distribution medium "Facebook". However, only those citizens have been reached who have an active Facebook account and use it on a daily basis. It should be critically noted that the relatively young average age of 31 years is also due to using this medium. It was positive that we were able to stimulate a discussion on Facebook by means of the survey. A further point of criticism of the work is the reduction to only four scientific fields or dimensions. Inclusion of natural science aspects that direct the influence on the local flora and fauna or issues of disposal and recycling of the resulting waste was not possible due to the limited scope of the work. In order to increase the quality of the survey, feedback for an additive survey on this topic, an additional personal survey would be useful. This would provide the opportunity to ask more in-depth questions in the case of particularly unusual or emotionally charged answers.

\subsection{Outlook, need for research and action}

In Schwäbisch Hall, there has been a ban on fireworks in the city centre for many years, but this was introduced due to fire protection measures. In this respect, pioneering work has been done, as this is the first publication to examine the subject of fireworks from an ecological, political, health and consumer point of view. The main need for action is to educate the citizens about the multidimensionality of effects linked to fireworks. After all, opinions are often only formed by including aspects like environmental protection. Only by considering all dimensions and aspects, a social rethinking regarding fireworks can take place. As New Year's Eve fireworks are a longstanding tradition, more profound studies and educational campaigns on a national level are necessary in order to change fundamental motives, values, and attitudes.

\section{References}

Acker, N. (2019, August 26). Manchen fehlt das Feuerwerk. SWP.de. https://www.swp.de/suedwesten/landkreise/lk-schwaebisch-hall/schwaebisch-hall-sommernachtsfestfeuerwerk-lasershow-32664517.html (visited: 05.12.2019) 
Alianza del Clima e.V. (n.d.). Städte und Gemeinden auf der ganzen Welt erklären Klimanotstand. https://www.klimabuendnis.org/kommunen/klimanotstand.html

Atteslander, P. (2010). Methoden der empirischen Sozialforscbung (13th edition). Erich Schmidt Verlag GmbH \& Co. KG, Berlin.

A. U. (2015): Verhaltensökonomik. WISU, (Issue 01/15): 53-55.

A. U. (2017): Die Menschen-Versteher. WISU, (Issue 11/17): 1200-1201.

A. U. (2018): Außer Kontrolle. WISU, (Issue 01/18): 20-22.

Badenberg, U. (2016). Nudging. WISU, (Issue 03/16): 283.

Balzert, H., Schröder, M. \& Schäfer, C. (2011). Wissenschaftliches Arbeiten (2nd edition). W3L GmbH, Herdecke.

Bischoff, M. (2014). Killer-Partikel—gefährlicher als Malaria. MMW-Fortschritte der Medizin, 156(7), 22-22.

Dechêne, C. (2016). Konsumentenverhalten. WISU, (Issue 8-9/16): 905-911.

Döring, N. \& Bortz, J. (2016). Forschungsmethoden und Evaluation (5th edition). Springer Verlag, Heidelberg.

Edeltraud, G., Plewnia, F., Hussy, C. \& Münch, S. (2015). Life Cycle Sustainability. WISU, (Issue 03/15):269-270.

Greta Thunberg (n. d.): Über uns. Fridays for Future. https:// fridaysforfuture.de/about/ (visited: 11.12.2019)

Greven, F. E., Vonk, J. M., Fischer, P., Duijm, F., Vink, N. M. \& Brunekreef, B. (2019). Air pollution during New Year's fireworks and daily mortality in the Netherlands. Scientific Reports, (Issue 04), pages 1-8. doi: 10.1038/s41598-019-42080-6

Held, B. (2019). Der Ökobonus - Instrument für eine sozial gerechte Umwelt- und Klimapolitik? Wirtschaftsdienst, (Issue 01): 53-60. https://www.wirtschaftsdienst.eu/inhalt/jahr/2019/heft/1 /beitrag/der-oekobonus-instrument-fuer-eine-sozial-gerechte-umwelt-und-klimapolitik.html

Huth, A., Löffler, L. \& Viestenz, A. (2019). Ocular Injuries From Fireworks in the Past 11 Years: Evaluation of the University Hospital and Polyclinic for Ophthalmology Halle. Ophthalmologe. 116(12):11711176. DOI: $10.1007 /$ s00347-019-0941-z

Li, J., Xu, T., Lu, X., Chen, H., Nizkorodov, S. A., Chen, J., Yang, X., Mo, Z., Chen, Z., Liu, H., Mao, J. \& Liang, G.(2016). Online single particle measurement of fireworks pollution during Chinese New Year in Nanning. Journal of Environmental Sciences (Cbina), (Issue 06/2016):184-195. doi: 10.1016/j.jes.2016.04.021

Morscher, C. (2015). Nachhaltigkeit. WISU, (Issue 06/15): 661.

Röhlig, M. (2020, May 8). Vor einem Jahr hat Konstanz den Klimanotstand ausgerufen - was hat die Stadt seither erreicht? Bento Magazine. https://www.bento.de/politik/klimanotstand-in-konstanz-waserreicht-wurde-und-wieso-nun-streit-droht-a-f137c8a9-e61d-4291-9a23-e8b926f3130c

Sandvall, B. K., Jacobson, L., Miller, E. A., Dodge, R. E., Quistberg, D. A., Rowhani-Rahbar, A., Vavilala, M. S., Friedrich, J. B. \& Keys, K. A. (2017). Fireworks type, injury pattern, and permanent impairment following severe fireworks-related injuries. American Journal of Emergency Medicine, 35: 1469-1473. doi: 10.1016/j.ajem.2017.04.053

Spannowsky, W. Der rechtliche Umgang mit gesundheitsgefährdenden Luftschadstoffen mit und ohne Grenzwerte: eine Doppelmoral im Lichte von Nachhaltigkeit und Umweltgerechtigkeit. NuR (41): 433-440. https://doi.org/10.1007/s10357-019-3542-3

Stadt Schwäbisch Hall (2019). Statistik über Einwohnerzablen in Schwäbisch Hall. https://www.schwaebischhall.de/de/unsere-stadt/statistik/zahlen-daten-fakten (visited: 02.12.2019)

Südwestrundfunk (2019). Konstanzer Seenachtfest 2020 doch mit Feuerwerk. SWR Aktuell. https://www.swr.de/swraktuell/baden-wuerttemberg/friedrichshafen/Konstanz-Seenachtfestwieder-mit-Feuerwerk,seenachtfest-feuerwerk-2020-100.html (visited: 05.12.2019)

Tanda, S., Ličbinský, R., Hegrová, J. \& Goessler, W. (2019). Impact of New Year's Eve fireworks on the size resolved element distributions in airbone particles. Environment International, (Issue 07/19): 371-378. https://doi.org/10.1016/j.envint.2019.04.071 